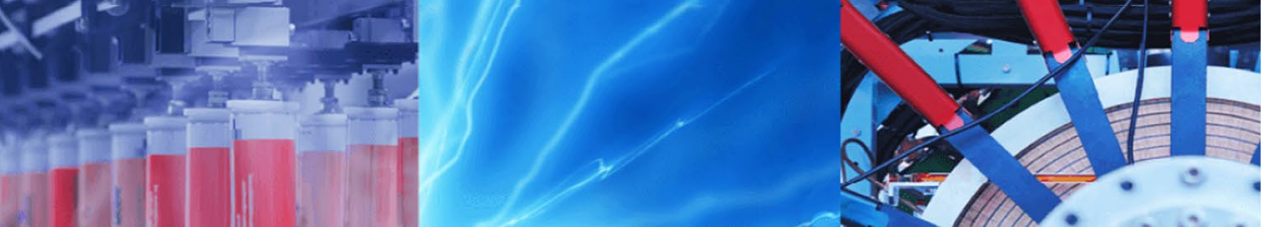

Research Article

\title{
Polythiophene coated poly(methyl methacrylate) sheet as a new candidate for flexible organic electrode applications
}

\author{
Ali Akbar Yousefi ${ }^{1}$ (D) \\ (c) Springer Nature Switzerland AG 2019
}

\begin{abstract}
Poly (methylmethacrylate) (PMMA) is an amorphous, flexible and transparent polymer. We benefited these properties of PMMA to replace glass in solar cells. To replace rigid indium-tin oxide coated glass, PMMA sheet was coated by polythiophene. To achieve this goal, PMMA was in situ coated by $\mathrm{FeCl}_{3}$-catalyzed polymerization of thiophene in acetronitrile at room temperature. Different catalyst concentrations and reaction times were checked. The optimum catalyst concentration was found to be $1.8 \mathrm{~g}$. Surface and cross-section morphologies of the coated layer were investigated using optical and scanning electron microscopes. At high catalysts concentration, a prolonged reaction time increased the polythiophene particles' diameters, whereas at low catalyst concentrations longer reaction timeswere found to be almost of no effect on particles' sizes. However, it was noted that the reaction time affects the thickness of the coated conductive layer on the substrate. The highest electrical conductivity was observed for a layer coated under optimized reaction conditions (that is, $1.8 \mathrm{~g}$ catalyst along with $20 \mathrm{~min}$ reaction time) with an electrical conductivity of $0.74 \mathrm{~S} / \mathrm{m}$ and a conductive layer thickness of 37 micrometers. The prepared fully polymer electrode is supposed to replace ITO or FTO coated glasses in some applications such as solar windows.
\end{abstract}

Keywords Polythiophene PMMA - Electrically-conductive polymer · Surface morphology · Organic electrode · Solar window · Transparent electrode

\section{Introduction}

The flexibility and light-weight are two main characteristics of polymers. Some polymers are semi-crystalline and opaque but some other polymers are amorphous and optically transparent. These properties of polymers altogether lead to very specific features which can be profited in different applications. PMMA is known as a substituent for glass [1] due to its transparency, good light transmittance and chemical resistance [2]. It is believed that if an amorphous transparent polymer can replace glass in solar cells, the demand for this polymer can be doubled [3]. In spite of favorable mechanical, optical and surface properties of PMMA, it is difficult to cover its films or sheets with a thin layer made from asemi-flexible conductive polymer such as polythiophene. Whenever difficulties of electrical conductive layercoating are overcome, PMMAwould be afavorite material to replace conventional materials such as glass sheets coated by conductive metallic oxides (e.g. indium thin oxide, ITO) which are usually used in electronics and energy harvesting applications. Notwithstanding excellent electrical conductivity and transparency of ITO layer, some inherent drawbacks of ITO are high price and temperature of manufacturing, rareness of indium, brittleness of ITO layer and increase in electrical resistance in large areas. Hence, the future of flexible electronics seeks for any commodity substitution for ITO in many different routes [4-6]. Moreover, in organic light emitting diodes (OLEDs) the large mismatch $(\sim 1.2 \mathrm{eV})$ between work function of ITO (anode) and the typical highest occupied

Ali Akbar Yousefi, a.yousefi@ippi.ac.ir| 'Department of Plastics, Faculty of Polymer Processing, Iran Polymer and Petrochemical Institute, P.O Box 14965-115, Tehran, Iran.

SN Applied Sciences (2019) 1:440 | https://doi.org/10.1007/s42452-019-0454-z 
molecular orbital (HOMO) of active polymer/organic molecule prohibits surmounting the barrier of hole transfer from ITO [7]. Meanwhile, some tried to prepare highly flexible and transparent layers at room temperature through some modifications $[8,9]$. This thin transparent conductive ITO layers on a given substrate are usually prepared using layer-deposition technique [10]. Transparency and electrical conductivity of ITO films are acceptable, but ITO layer are still brittle on the flexible substrates and show some bending limitations $[11,12]$.

Carbon nanotubes along with different conductive polymers are used to improve electrical conductivity of polymeric layers [13, 14]. Graphene sheets are also coated on polymer substrates to prepare conductive transparent layers $[15,16]$. Nowadays, conductive polymers in different applications have replaced conventional conductive materials such as ITO. Flexible electronic devices are the main target of conductive polymers [17]. Some polymer composite fibers [18] and textiles [19] based on inherently non-conductive polymers are also developed which show electrical conductivity. The inherent conductivity of conjugated conductive polymers such as derivatives of polythiophene grants the polymer some special properties such as electroluminescence as well [20]. These polymers emit light in full range of visible spectrum and become very attractive in the field of printed optoelectronics. Conductive polymers were admixed with metallic powders to yield conductive inks for divers printing techniques applicable in flexible electronics. PEDOT:PSS [poly(3,4-ethylenedi oxythiophene):poly(styrene sulfonate)] is used in inkjet conductive printing in pure form [21] or in form of nanocomposite with single-walled carbon nanotubes [22]. The pure film of this conductive polymer is used to inkjet print patterns of flexible solar cells [23]. A review of the printing techniques such as inkjet which could be employed in flexible electronics is available [24]. The state of the art of the technologies of printing polymer solutions [25] and flexible electronics is developed in roll-to-roll process [26]. This technology leads to a cost effective process to produce light-weight, low-price and highly flexible circuit boards for reliable and heavy duty electronic devices. In addition to the electronic boards, the conductive polymers are also used in rechargeable lithium batteries [27]. Some research teams have worked on conductive polymer coatings on polymeric substrates such as transparent flexible films of poly ethylene terephthalate (PET) [28-31] and piezoelectric, semi-transparent and flexible PVDF nano-composite films [32].

As said, poly(methylmethacrylate) (PMMA), a solutioncast low-temperature processed material, is a transparent amorphous polymer with a relatively high glass-transition temperature $\left(T_{g}=105^{\circ} \mathrm{C}\right)$ [33]. Due to its low cost, PMMA can be integrated in building components such as windows and floating tiles while it bears a conductive polymer coating such as polythiophene, polyaniline or polypyrrole [34]. A review of scientific literature reveals that PET films and sheets are overwhelmingly used as substrate for conductive polymeric coatings. PET, a semicrystalline polymer, its transparency is less than that of PMMA. PET thin films' transparency is good, but its thicker sheets cannot be used in building integrated photovoltaics (BIPVs) [35]. PMMA is an effective polymer in protection of conductive polymers such as poly(3-hexylthiophene) (P3HT)and poly[2-methoxy-5-(39,79-dimethyloctyloxy)1,4-phenylenevinylene](MDMO-PPV) against oxidation. Therefore, using the couple of PMMA and a conductive polymer layer could be resulted in a replacement for glassITO brittle couple [36].

This paper report facile and low-price technique for preparation of a transparent flexible electrode using fully amorphous, transparent and flexible poly(methylmethacrylate) sheet under proper conductive polymer layer deposition conditions using $\mathrm{CH}_{3} \mathrm{CN}$ as polymerization medium. The morphology of the surface and cross-section of the coated layers were also investigated using scanning electron and optical microscopes. The electrical properties of the coated layers are also reported.

\section{Experimental}

\subsection{Materials}

Both thiophene and $\mathrm{FeCl}_{3}$ were purchased from Merck Company (Darmstadt, Germany). Acetonitrile was also purchased from Dae Jung Company (Korea). PMMA substrate was procured from Year Long Industrial Company limited (Taiwan). The PMMA sheets are of $1 \mathrm{~mm}$ thickness and are transparent and produced via solution casting technique. The flexibility of the used PMMA sheet is represented in Fig. 1a. Some physical properties of the PMMA sheet are available [37].

\subsection{Methods}

\subsubsection{Layer deposition}

The monomer solution was prepared by mixing $2.5 \mathrm{ml}$ thiophene with $50 \mathrm{ml}$ acetonitrile. The catalyst or oxidant solution was prepared by dissolving $9 \mathrm{~g} \mathrm{FeCl}_{3}$ in $100 \mathrm{ml}$ acetonitrile. Both solutions were separately agitated for $20 \mathrm{~min}$. Prior to reactive coating on PMMA sheet, its protective paper adhesives were discarded and sheet was washed out by soap solution and rinsed by water. Then the PMMA sheet was clamped and suspended in a beaker 

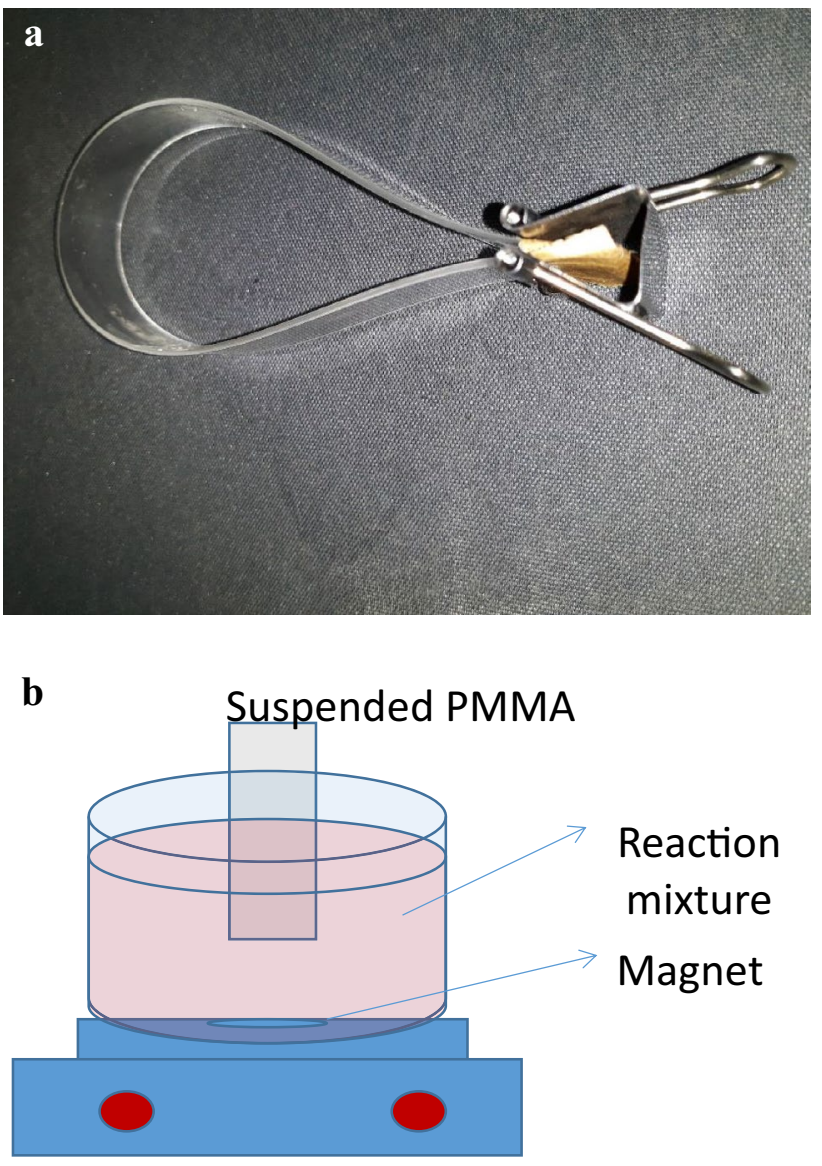

Heater stirrer

Fig. 1 a A representation of PMMA sheet flexibility. $\mathbf{b}$ Schematic of reaction vessel

contained stirred oxidant solution. To form polythiophene conductive layer on PMMA sheet, the monomer solution was added to the reaction beaker drop-wise and stirred for a given reaction time (Fig. 1b). As polymerization reaction proceeds, the reaction mixture darkens. The molar ratio of oxidant/monomer was fixed at $1 / 5$. The synthesized and deposited samples were coded based on catalyst concentration and reaction time (Table 1 ).

\subsubsection{Characterization}

The electrical conductivity of coated samples was measured using four-point microprobe device from Sanat Nama Javan Company (FPP-SN-554 model, Iran). Surface morphology and EDX pattern of layers was studied using scanning electron microscopy (VEGA/TESCAN, Czech Republic). The SEM samples were sputtered with gold before the test. The Fourier transformed infrared spectroscopy (FT-IR) spectra of the layers was obtained using Bruker Equinox 55 model in attenuated total reflectance (ATR) mode. The
Table 1 Reaction conditions, morphological and optical parameters of polythiophene layers coated on PMMA substrate

\begin{tabular}{lllll}
\hline Sample & $\mathrm{FeCl}_{3}(\mathrm{~g})$ & $\begin{array}{l}\text { Reaction } \\
\text { time }(\mathrm{min})\end{array}$ & $\begin{array}{l}\text { Mean particle } \\
\text { diameter }(\mathrm{nm})\end{array}$ & $\begin{array}{l}\text { Conductive } \\
\text { layer thickness } \\
(\mu \mathrm{m})\end{array}$ \\
\hline Th2.5-12 & 2.5 & 12 & $113 \pm 35$ & 50.79 \\
Th2.5-20 & 2.5 & 20 & $281 \pm 81$ & 69.93 \\
Th1.8-12 & 1.8 & 12 & $101 \pm 36$ & 51.42 \\
Th1.8-20 & 1.8 & 20 & $94 \pm 30$ & 36.68 \\
Th1.76-12 & 1.76 & 12 & $76 \pm 35$ & 30 \\
Th1.62-12 & 1.62 & 12 & $106 \pm 31$ & 41.38 \\
\hline
\end{tabular}

optical microscope images of the coated surfaces were obtained using an Olympus CX21 microscope at 10X magnification.

\section{Results and discussion}

\subsection{FT-IR spectroscopy}

In Fig. 2a the FT-IR spectrum of the as received PMMA substrate is shown. In this spectrum the absorption band at $1736 \mathrm{~cm}^{-1}$ assigned to $\mathrm{C}=\mathrm{O}$ stretching. Other bands at $1437-1490,1070$ and $1196 \mathrm{~cm}^{-1}$ are assigned to $\mathrm{O}-\mathrm{CH}_{3}$ deformation, $\mathrm{O}-\mathrm{CH}_{2}$ stretching vibrations and $\mathrm{C}-\mathrm{O}$ stretching vibrations, respectively [38]. The intensity of the absorption bands is strong. This stems from the transparency of the PMMA sheet. The FT-IR spectrum of layer coated on PMMA is also shown in Fig. 2b. The bands at 1674 and $1404 \mathrm{~cm}^{-1}$ are assigned to symmetric and asymmetric stretching vibrations of $C=C$ bonds of thiophene ring, respectively. Absorption bands of thiophene appear at $763 \mathrm{~cm}^{-1}$ (C-S bending) and $694 \mathrm{~cm}^{-1}$ (stretching-deformation of C-S-C of ring) [39]. The intensity of the peaks in Fig. $2 b$ is less than that in Fig. 2a. The lost of intensity in Fig. $2 \mathrm{~b}$ is mainly related to the technique of attenuated FT-IR in which infrared radiation travels a short path inside the sample [40]. The differences between the reported spectra confirm formation of polythiophene on the surface of the PMMA substrate.

\subsection{Morphology}

\subsubsection{Scanning electron microscopy}

Two different samples were prepared for morphological study of the samples; one for surface morphology of the samples and the other one for bulk and thickness measurement of the coated layers. The surface morphology of the samples is shown in Figs. 3, 4, 5, 6, 7 and 8. As seen, surface morphologyof the coated conductive layers are 
Fig. 2 a FT-IR spectrum of PMMA substrate. b FT-IR spectrum of polythiophene coated on PMMA substrate
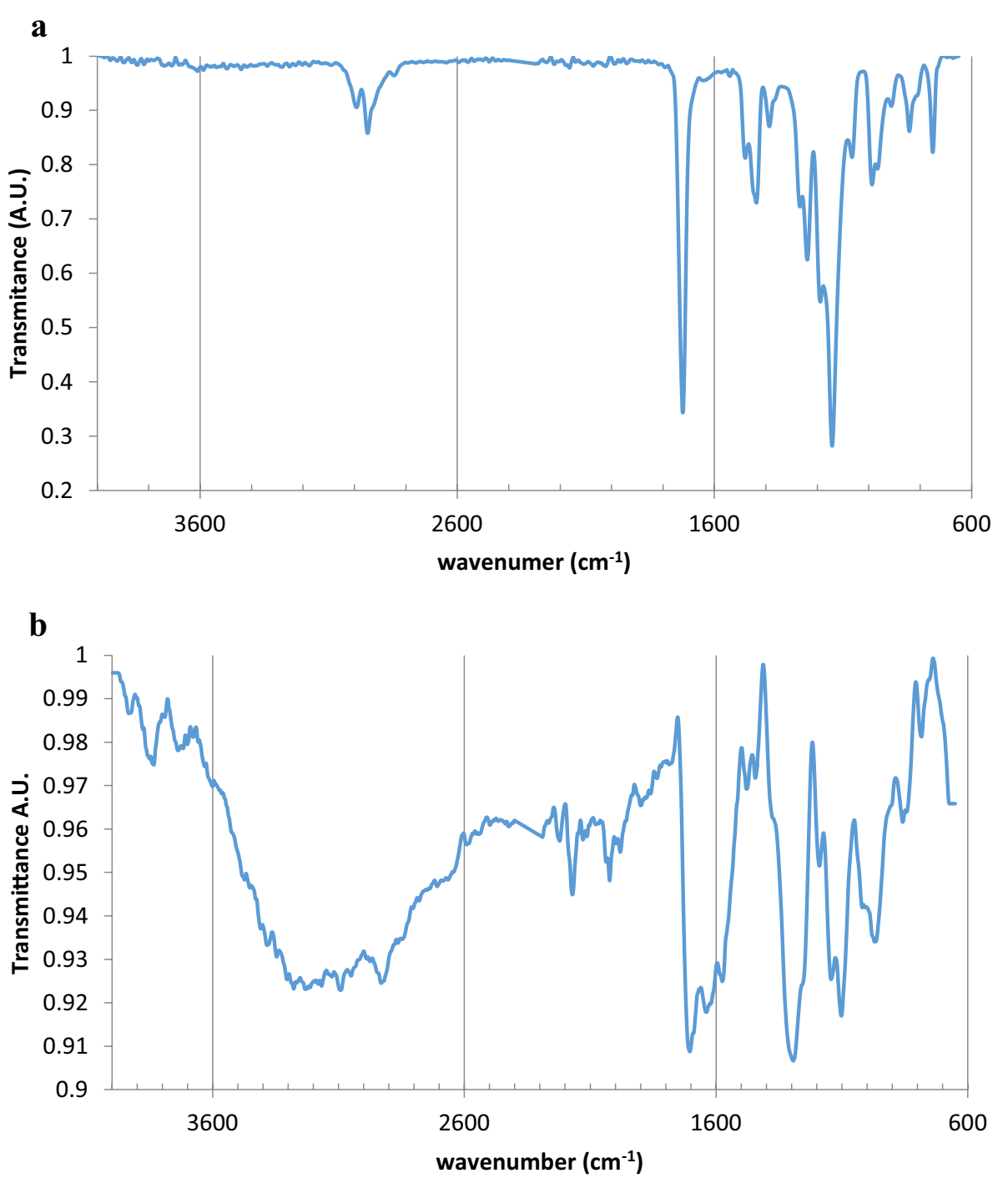

almost the same at high magnification for all reaction conditions. However, at low magnification the surface morphology of the coated layers are very different. Amongst these samples Th2.5-20 shows a very different surface morphology at both levels of magnification. It seems that under these conditions at high catalyst concentration and long reaction time the synthesized conductive polythiophene layer becomes more condensed and a lower concentration of voids are formed. Meanwhile, at higher catalyst concentration more active polymerization sites exist and during a longer reaction time. Formation of larger polymer particles is favored. Agglomeration of polymer particles leads to a coarser surface morphology.

The diameter of the distinguishable particles forming the conductive layers Figs. 3b, 4a, b are measured using Image J software and reported in Table 1 (other highmagnification SEM micrographs are not reported for the sake of brevity). Finding a relation between reaction conditions and particle size is complicated. According to the figures and Table 1, both reduced catalyst concentration and shortened reaction time result in particle size reduction. A reverse effect on polymer particle size in $\mathrm{FeCl}_{3} /$ $\mathrm{H}_{2} \mathrm{O}_{2}$ (catalyst/oxidant) found with $\mathrm{H}_{2} \mathrm{O}_{2}$ concentration [41]. It resulted from difference in initiator system for noncoated polymer particles. It seems that at different radical concentrations, reaction time differently affects particles morphology. For example, at the same reaction time (say $12 \mathrm{~min}$ ) reducing catalyst concentration leads to a reduction in number of active centers and a lower total polymer formation rate. This reduces size of particles in the conductive coating layer. At the same catalyst concentration, a shorter reaction time leads to coagulation of polymer chains and favors formation of larger particles.

At low magnification some cracks are observed which are to be discussed on SEM images of sample crosssections. At large scale (low magnification) according to the observed surface texture it seems that some parts of PMMA substrate is not covered by conductive polymer. In 

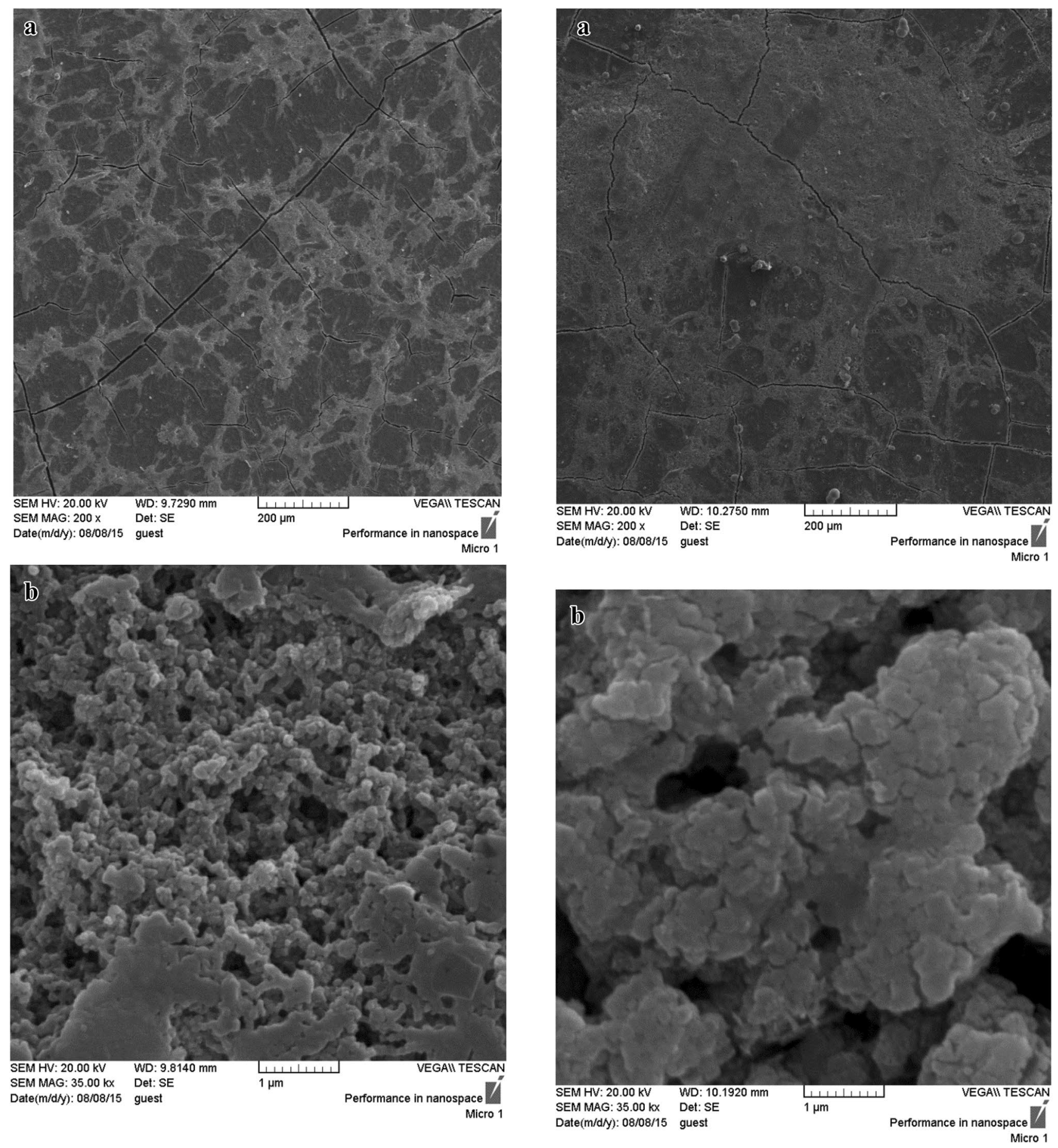

Fig. 3 a Large scale surface morphology of Th2.5-12 sample. b A close-up of surface morphology of Th2.5-12 sample

Fig. 9a the cross-section of sample Th2.5-12 is represented. A top layer with a thickness of around 50 microns is distinguishable. The EDX map for chlorine (green points) and iron (red points) is shown in Fig. 9b. As seen, the top layer is crowded by chlorine and iron atoms, which is an evidence for formation of polythiophene on PMMA substrate. Some scattered points out of top layer are observed which could

Fig. 4 a Large scale surface morphology of Th2.5-20 sample. b A close-up of surface morphology of Th2.5-20 sample

be displaced during SEM sample preparation. Some cracks are observed on the conductive layer which could be formed due to conductive layer shrinkage (crystallization).

The SEM micrograph of the cross-section of other samples is not reported here for the sake of brevity but the measured thicknesses are reported in Table 1. As seen 


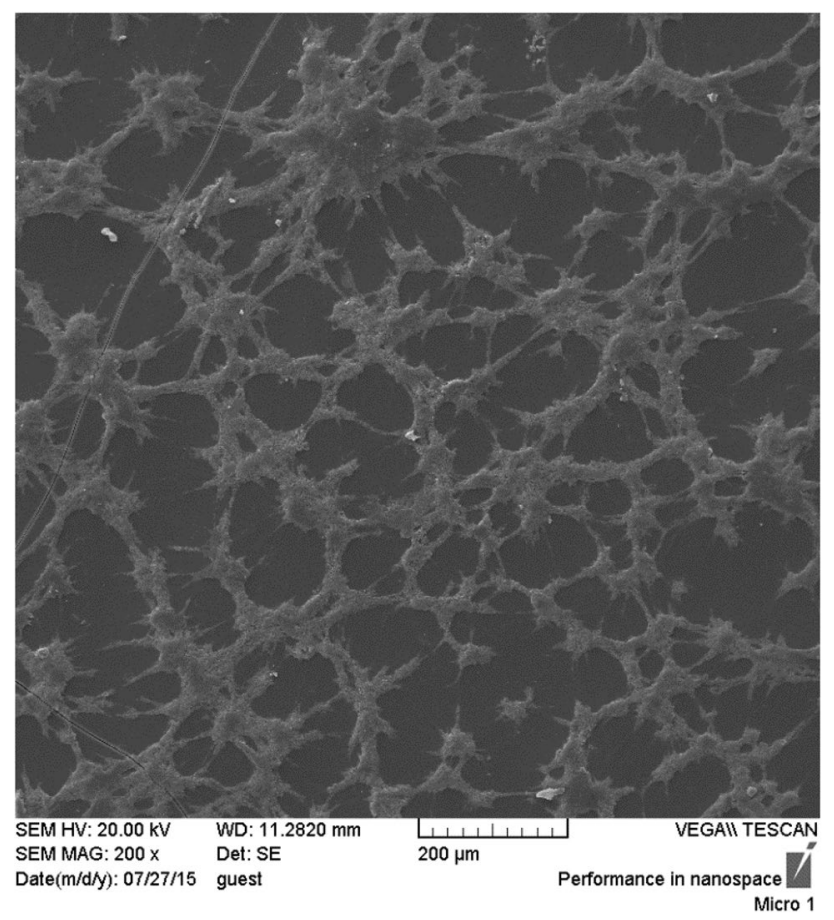

Fig. 5 Large scale surface morphology of Th1.8-20 sample

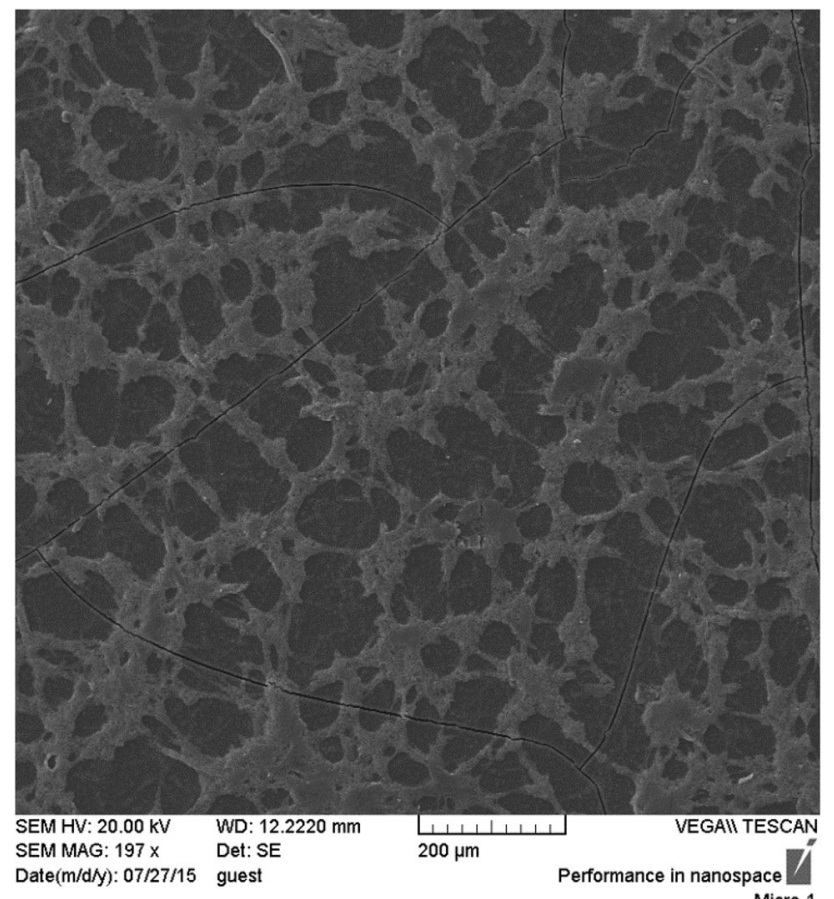

Fig. 6 Large scale surface morphology of Th1.8-12 sample

in Table 1 the thickness of the coated conductive layers ranges between 30 and 70 microns. As a general

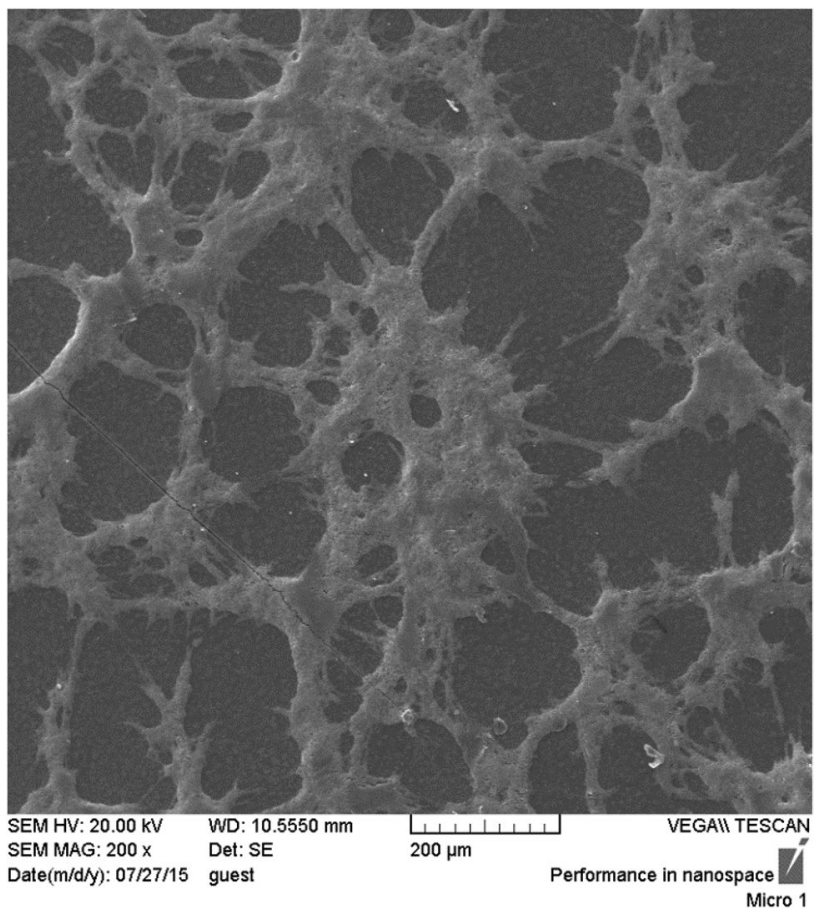

Fig. 7 Large scale surface morphology of Th1.76-12 sample

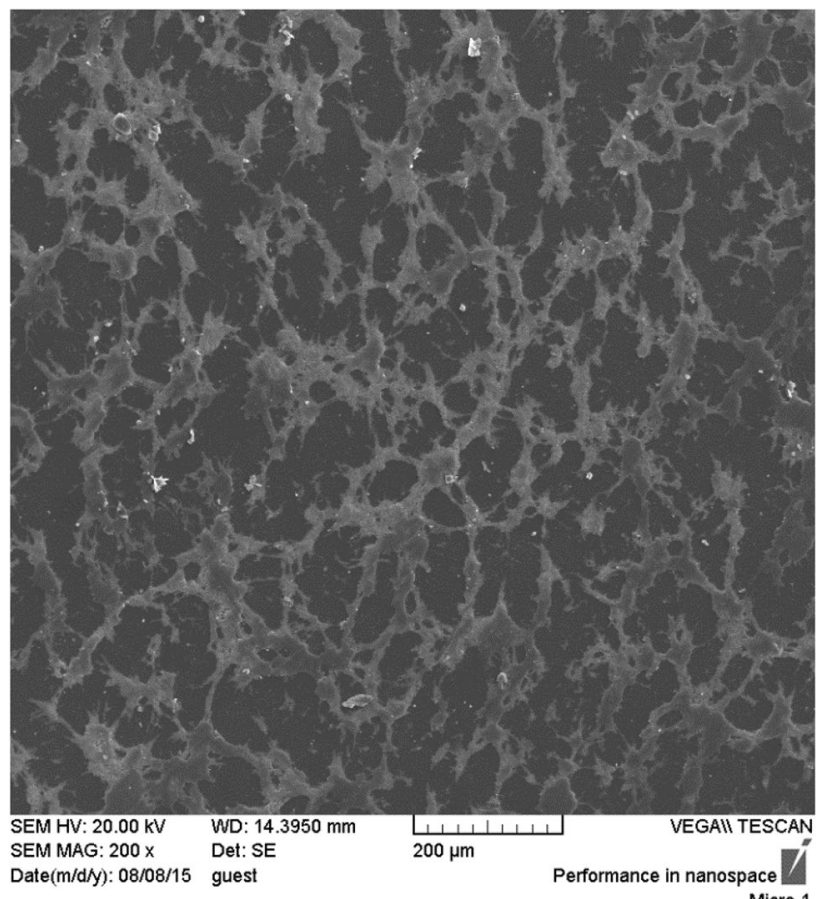

Fig. 8 Large scale surface morphology of Th1.62-12 sample

conclusion both catalyst $\left(\mathrm{FeCl}_{3}\right)$ concentration and reaction time affect the thickness of the coated conductive layer.

\section{SN Applied Sciences}



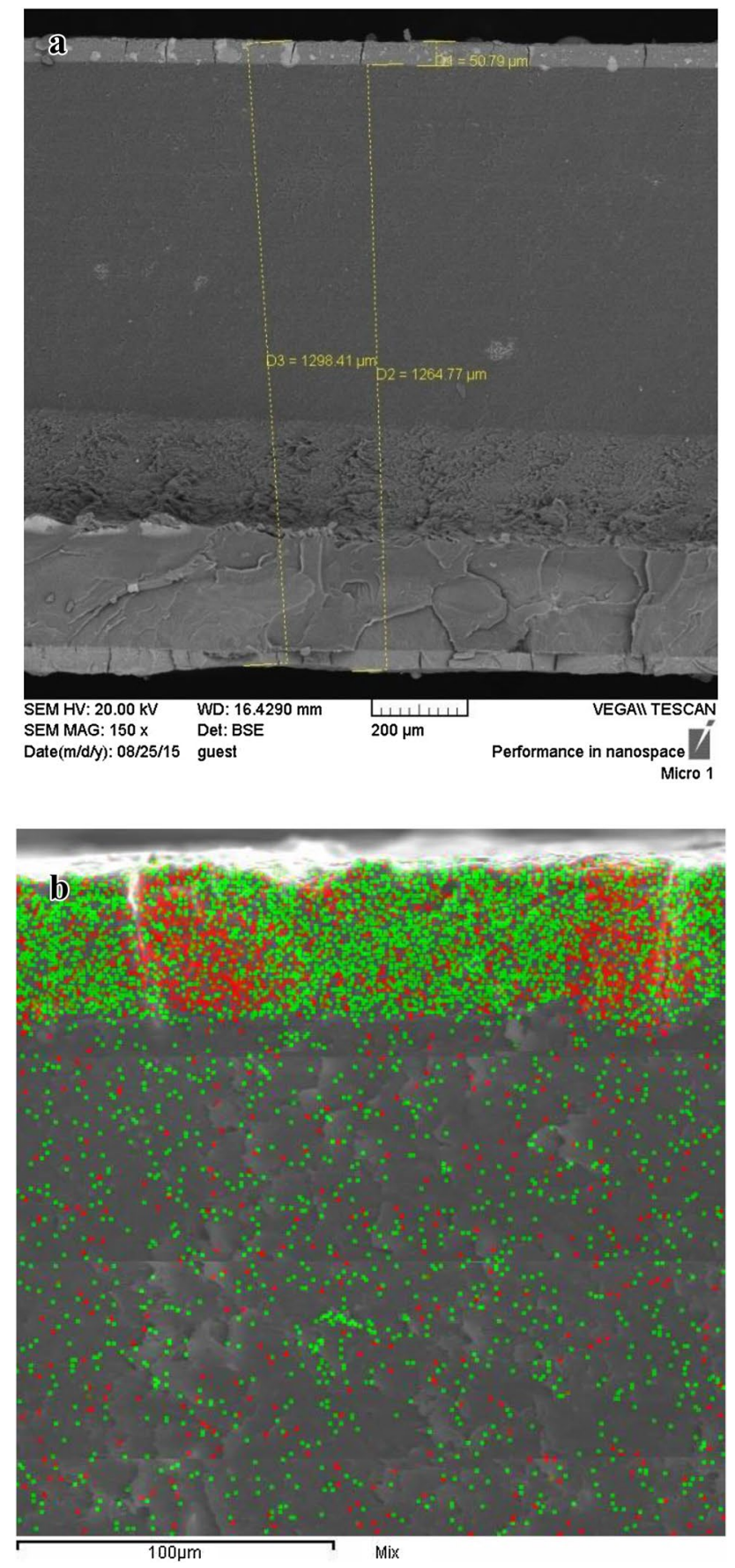

Fig. 9 a SEM view of Th2.5-12 sample cross-section. $\mathbf{b}$ EDX map of chlorine (green points) and iron (red points) of Th2.5-12 sample cross-section

\subsubsection{Optical microscopy}

Electron scanning microscopy does not depict sample surface in color in spite of its high resolution. However, one may claim that sample preparation and electron irradiation of a conductive polymer may change the polymer structure. Meanwhile, an optical microscope in reflection

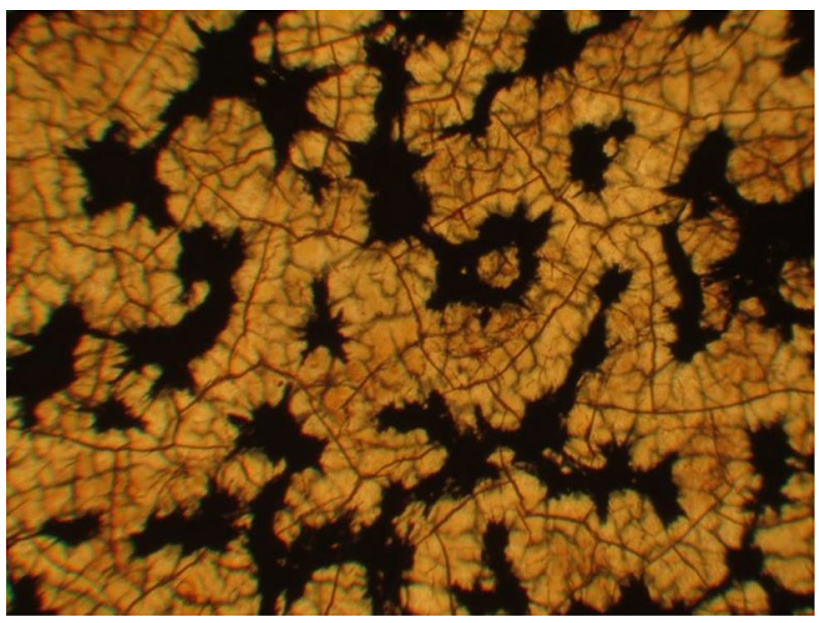

Fig. 10 Optical microscope image of Th1.8-12 surface

mode captures color images of a surface without any risk of structural change at the expense of a lower magnification. This advantage was taken using a laboratory optical microscope to envisage the surface of coated polythiophene on PMMA sheet in color. A typical optical microscope picture of the surface of the coated layers is presented in Fig. 10. Due to narrow focal distance only the upper surfaces are observed in yellow color whereas the surface shallow valleys are appeared in black. These images reveal a special surface morphology for the coated conductive layer. Another important observation is the existence of cracks on the coated conductive layers which are formed due to top layer contraction. These structural defects were proposed to be formed due to heterogeneous microstructure [42]. According to Wang and Feng [42], to avoid these cracks the thickness of the conductive polymer layer should be kept below 10 microns. The coated layers of our samples are thicker than 10 microns which means the crack defects are to be formed. However, we may use the term of semi crystalline structure instead of heterogeneous microstructure used by Wang and Feng [42]. At thicknesses below 10 microns polythiophene crystallization is not able to induce cracks in the coated films. However, in the thicker films the polymer crystals' growth could be large enough to crack the film. In another paper in by these authors [43] the concept of island was used for this heterogeneous structure which our optical microscope images are also bring the same concept in the mind. According to the authors whenever the film thickness gets 2-3 times larger than the height of the island ( $h \sim 1-2$ micrometers for polythiophene on stainless steel substrate) the effect of the substrate on film reduces and the conductive film starts to crack. These cracks should negatively influence electrical conductivity of the layers. The observed morphology using optical microscope is 
almost the same as that was viewed by SEM. These optical images confirm inertness of SEM technique on the film morphology and refuse any technical artifact on the film surface.

\subsubsection{Electrical properties}

In Fig. 11 the measured 4-probe electrical resistance and corresponding calculated electrical conductivity are reported. The higher precision of 4-point measurement stems from separation of current and voltage electrodes which leads to elimination of lead and contact resistance of the measurement [44]. This makes 4-probe technique favorable for low-resistance measurements. This can be concluded that the low resistance materials such as semiconductors and conductive polymers should be tested using 4-probe device. In case of the first two samples reaction times are different, but catalyst concentration is the same. Doubling the reaction time only leads $20 \%$ increase in thickness of the conductive layer. However, according to Fig. 11 the resistance is almost doubled and the layer conductivity is reduced 2.5 orders of magnitude. The nonlinearity of the layer thickness increase with reaction time should be related to the competition between polymer precipitation and polymer deposition on PMMA surface. According to Wang and Feng [43] an increase in conductive layer thickness would results in island formation followed by cracking. This would results in a longer electrical path for electrical current which in turn increases resistance (decrease in conductivity) (Fig. 12). The islands are interconnected on the PMMA substrate and are separated at higher layer heights (Fig. 9a). It means that any electrical current applied on the surface of the conductive layer

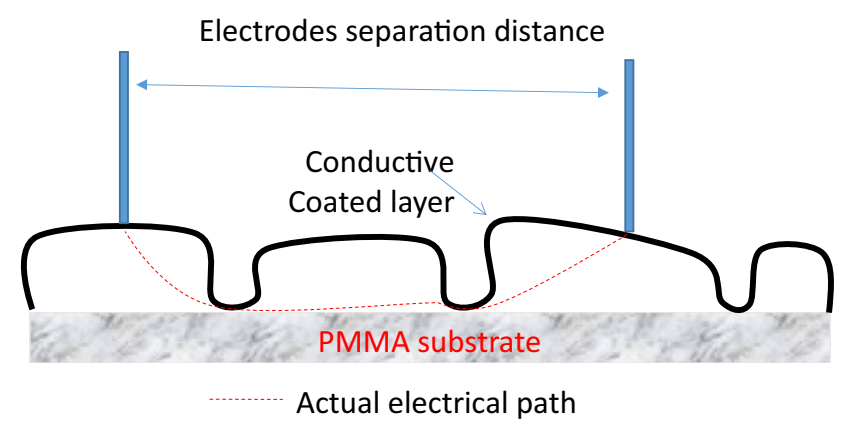

Fig. 12 Depiction of difference between electrodes separation distance and actual electrical path

are to travel downward to the PMMA surface to reach the counter electrode. All these mean a longer electrical path or a higher resistance and lower conductivity.

In case of the second two samples the catalyst concentration is lower than that of the first two samples. Here a prolonged reaction time leads to $30 \%$ reduction in conductive layer thickness. This could be a result of preferential polymer precipitation during longer reaction time in the presence of lower catalyst concentration. A lower catalyst concentration does not favor polymer deposition. Consequently, a thinner polymer layer is deposited on the PMMA substrate. However, based on the argument made for the first couple of the samples due to shorter path formed between the electrodes of the measuring device, Th1.8-20 sample represents the highest electrical conductivity. A stepwise reduction of catalyst concentration in case of the last two samples at constant reaction time (12 $\mathrm{min}$ ) leads to a constant conductivity of the coated layer followed by conductivity reduction. After
Fig. 11 Electrical properties of polythiophene coated on PMMA sheet under different reaction conditions

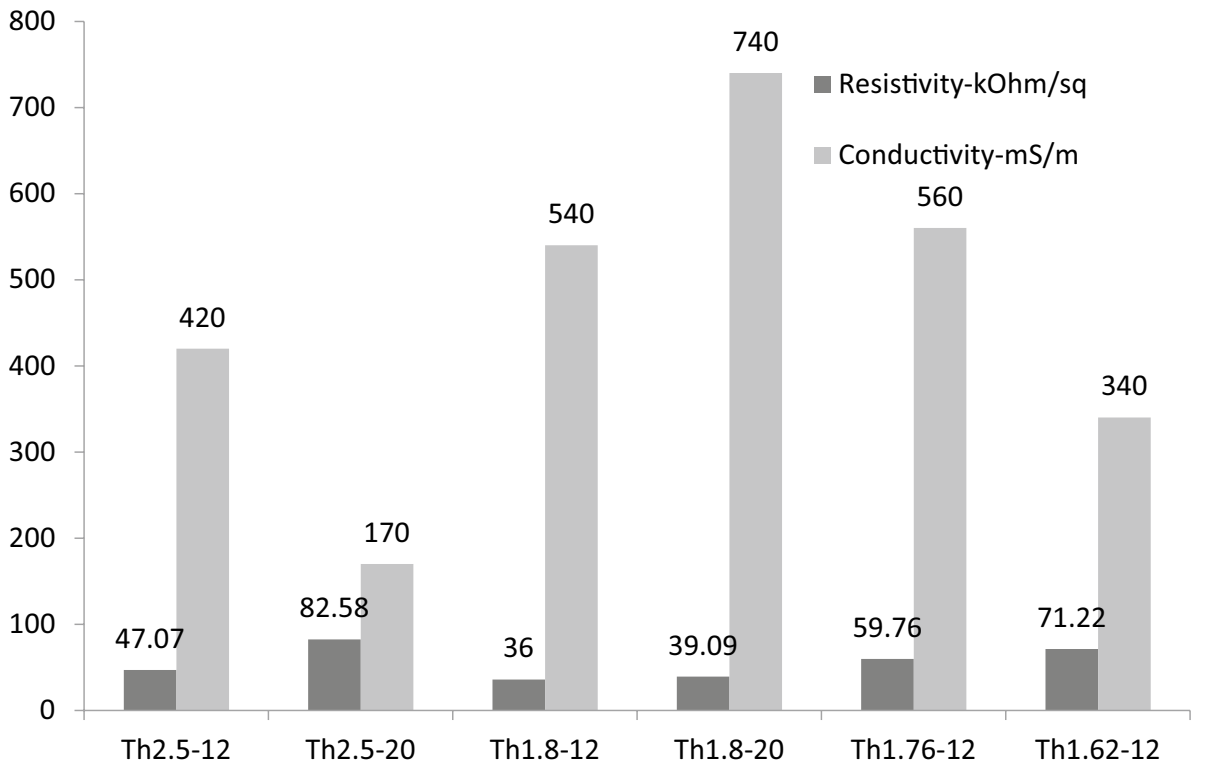


polymerization the catalyst also acts as doping agent for the conductive polymer. Therefore, it is normal to expect that at low catalyst concentration the conductivity of the deposited layer decreases. As it is the case for the two last samples.

\section{Conclusion}

A transparent conductive polymer layer on a transparent polymer substrate was prepared through polymerization deposition technique using acetonitrile as reaction system solvent. Formation of polythiophene conductive polymer was approved using FT-IR technique. The SEM images proved the formation of layer and its morphology. Depending on catalyst concentration and reaction time variations result in the particle size of the deposited polymer changes. Particle size increases at high catalyst concentration whereas the particle size almost remains constant at lower concentrations. Thinner layers show lower electrical resistance (higher electrical conductivity) due to shorter electrical path between measuring electrodes. The 4-probe device is recommended for thin-polymer layers. The thickness of the coated conductive layer of different samples varies between 30 and 70 micrometers. The optimum catalyst concentration was found to be around $1.8 \mathrm{~g}$ for a reaction time of $20 \mathrm{~min}$.

Acknowledgements This study was funded by Iranian National Science Foundation (Grant Number 93008296).

\section{Compliance with ethical standards}

Conflict of interest Author declares that there is no conflict of interests.

\section{References}

1. Ghorbani M, Fazli S, Soleimani Lashkenari M (2016) Fabrication of PMMA/PANI/Fe3O4 as a novel conducting hybrid coating. Polym-Plastic Tech Eng 37:591-599

2. Shah R, Kausar A, Muhammad B (2015) Exploration ofpolythiophene/graphene, poly(methyl methacrylate)/graphene and polythiophene-copoly(methyl methacrylate)/graphenenanocomposite obtained via in situ technique. J Plastic Film Sh 31:144-157

3. https://www.plasticstoday.com/content/solar-photovoltaicboom-could-double-demand-pmma-film/61720887915625

4. Lu S, Sun Y, Ren K, Liu K, Wang Z, Qu S (2018) Recent development in ITO-free flexible polymer solar cells. Polymers 10:5-35

5. Guo X, Liu X, Lin F, Li H, Fan Y, Zhang N (2015) Highly conductive transparent organic electrodes with multilayer structures for rigid and flexible optoelectronics. Sci Rep 5:10569

6. Kim JH, Joo CW, Lee J, Seo YK, Han JW, Oh JY, Kim JS, Yu S, Lee JH, Lee J-I, Yun C, Choi BH, Kim YH (2016) Highly conductive PEDOT:PSS films with 1,3-dimethyl-2-imidazolidinone as transparent electrodes for organic light-emitting diodes. Macromol Rapid Commun 37:1424-1433. https://doi.org/10.1002/ marc.201600144

7. Mauger SA, Moulé AJ (2011) Characterization of new transparent organic electrode materials. Org Electron 12:1948-1956

8. Yun J, Park YH, Bae T-S, Lee S, Lee G-H (2013) Fabrication of a completely transparent and highly flexible ITO nanoparticle electrode at room temperature. ACS Appl Mater Interfaces 5:164-172

9. Ghosh DS, Liu Q, Mantilla-Perez P, Chen TL, Mkhitaryan V, Huang M, Garner S, Martorell J, Pruneri V (2015) Highly flexible transparent electrodes containing ultrathin silver for efficient polymer solar cells. Adv Funct Mater 25:7309-7316

10. http://www.thinfilmproducts.umicore.com/

11. Alzoubi K, Hamasha MM, Lu S, Sammakia B (2011) Bending fatigue study of sputtered ITO on flexible substrate. J Display Tech 7:593-600

12. Jung HS, Eun K, Kim YT, Lee EK, Choa S-H (2017) Experimental and numerical investigation of flexibility of ITO electrode for application in flexible electronic devices. Microsyst Technol 23:1961-1970. https://doi.org/10.1007/s00542-016-2959-3

13. Zhang D, Ryu K, Liu X, Polikarpov E, Ly J, Tompson ME, Zhou C (2006) Transparent, conductive, and flexible carbon nanotube films and their application in organic light-emitting diodes. Nano Let 6:1880-1886

14. FallahdoostMoghadam S (2016) MSc thesis, Preparation of nanometric conductive polymer multi-layers on polymeric substrate, Islamic Azad University, North Tehran Branch, Iran (in Persian)

15. Berendjchi A, Khajavi R, Yousefi AA, Yazdanshenas ME (2016) Surface characteristics of coated polyester fabric with reduced graphene oxide and polypyrrole. Appl Surf Sci 367:36-42

16. Berendjchi A, Khajavi R, Yousefi AA, Yazdanshenas ME (2016) Improved continuity of reduced graphene oxide on polyester fabric byuse of polypyrrole to achieve a highly electro-conductive and flexible substrate. Appl Surf Sci 363:264-272

17. Mecerreyes D, Marcilla R, Ochoteco E, Grande H, Pomposo JA, Vergaz R, Sánchez Pena JM (2004) A simplified all-polymer flexible electrochromic device. Electrochim Acta 49:3555-3559

18. Kim B, Koncar V, Devaux E (2004) Electrical properties of conductive polymers: PET-nanocomposites' fibers. AUTEX Res J 4:9-13

19. Feller JF, Grohens Y (2004) Evolution of electrical properties of some conductive polymer composite textiles with organic solvent vapours diffusion. Sens Actuators B 97:231-242

20. Perepichka IF, Prepichka DF, Meng H, Wudl F (2005) Light emitting polythiophenes. Adv Matter 17:2281-2305

21. Perinka N, Kim CH, Kaplanova M, Bonnassieux Y (2013) Preparation and characterization of thin conductive polymer films on the base of PEDOT:PSS by ink-jet printing. Phys Procedia 44:120-129

22. Angelo PD, Cole GB, Sodhi RN, Farnood RR (2012) Conductivity of inkjet-printed PEDOT:PSS-SWCNTs on uncoated papers. Nordic Pulp Paper Res J 27:486-495

23. Eom SH, Senthilarasu S, Uthirakumar P, Yoon SC, Lim J, Lee C, Lim HS, Lee J, Lee S-H (2009) Polymer solar cells based on inkjetprinted PEDOT:PSS layer. Org Electronics 10:536-542

24. Yin ZP, Huang YA, Bu NB, Wang XM, Xiong YL (2010) Inkjet printing for flexible electronics: materials, processes and equipments. Chin Sci Bull 55:3383-3407

25. deGans B-J, Duineveld PC, Schubert US (2004) Inkjet printing of polymers: State of the art and future developments. Adv Mater 16:203-213

26. Apilo P (2015) Roll-to-roll printing of organic photovoltaic cells and modules. Ph.D dissertation, VTT Technical Research Centre of Finland Ltd

27. Scrosati B (1998) Conducting polymers: advanced materials for new design, rechargeable lithium batteries. Polym Int 47:50-55 
28. Foroutani K, Pourabbas B, Sharif M, Mohammadizadeh M, Fallahian M, Khademi S (2014) Preparation of conductive flexible films by in situ deposition of polythiophene nanoparticles on polyethylene naphthalate. Mater Sci Semicond Proc 18:6-14

29. Foroutani K, Pourabbas B, Sharif M, Fallahian M, Khademi S, Mohammadizadeh M (2014) In situ deposition of polythiophene nanoparticles on flexible transparent films: effect of the process conditions. Mater Sci Semicond Proc 19:57-65

30. Mohammadizadeh M, Pourabbas B, Mahmoodian M, Foroutani K, Fallahian M (2014) Facile and rapid production of conductive flexible films by deposition of polythiophene nanoparticles on transparent poly(ethyleneterephthalate): electrical and morphological properties. Mater Sci Semicond Proc 20:74-83

31. Mohammadizadeh M, Pourabbas B, Foroutani K, Fallahian M (2015) Conductive polythiophene nanoparticles deposition on transparent PET substrates: Effect of modification with hybrid organic-inorganic coating. Int J Eng Trans A: Basics 28:567-572

32. Mohammadizadeh M, Yousefi AA (2016) Deposition of conductive polythiophene film on a piezoelectric substrate: effect of corona poling and nano inclusions. Iran Polym J 25:415-422

33. Gedde UW (2001) Polymer physics. Springer, Berlin, p 79

34. Sackey SS, Vowotor MK, Owusu A, Mensah-Amoah P, Tatchie ET, Sefa-Ntiri B, Hood CO, Atiemo SM (2015) Spectroscopic study of UV transparency of some materials. Environ Pollut 4:1-17

35. Aim Market Insights, Global Building Integrated Photovoltaic: 2014-2022, November, 2016

36. Früh A, Egelhaaf H-J, Hintz H, Quinones D, Brabec CJ, PeisertH Chassé T (2018) PMMA as an effective protection layer against the oxidation of P3HT and MDMO-PPV by ozone. J Mater Res 33:1891-1901
37. http://www.yearlong.com.tw/ENGLISH/General_Purpose_Sheet s_2.html

38. Tomar AK, Mahendia S, Kumar Sh (2011) Structural characterization of PMMA blended with chemically synthesized PAni. Adv Appl Sci Res 2:327-333

39. Nasrollahzadeh $M$, Jahanshahi $M$, Salehi $M$, Behzad $M$, Nasrollahzadeh $\mathrm{H}$ (2013) Synthesis and characterization of nanostructured polythiophene in aqueous medium by soft-template method. J Appl Chem 8:31-34

40. https://en.wikipedia.org/wiki/Attenuated_total_reflectance

41. Lee SJ, Lee JM, Cho H-Z, Koh WG, Cheong IW, Kim JH (2010) Poly(thiophene) nanoparticles prepared by Fe3 -catalyzed oxidative polymerization: A size-dependent effect on photoluminescence property. Macromolecules 43:2484-2489

42. Wang X-S, Feng X-Q (2002) Effects of thickness on mechanical properties of conducting polythiophene films. J Mater Sci Lett 21:715-717

43. Wang X-S, Tang H-P, Li X-D, Hua X (2009) Investigations on the mechanical properties of conducting polymer coating-substrate structures and their influencing factors. Int J Mol Sci 10:52575284. https://doi.org/10.3390/ijms10125257

44. https://en.wikipedia.org/wiki/Four-terminal_sensing

Publisher's Note Springer Nature remains neutral with regard to jurisdictional claims in published maps and institutional affiliations. 